\title{
ADMINISTRAÇÃO EDUCACIONAL COMO PROCESSO DE MEDIAÇÃO INTERNA E EXTERNA A ESCOLA
}

\author{
José Camilo dos Santos Filho* \\ Maria Lúcia R.D. Carvalho* \\ Clara Germana de Sá Gonçalves**
}

\section{RESUMO}

Este estudo foi inșirado na constação de que a direção de uma organização especializada como a escola, é crucial para o seu efetivo desenvolvimento.

A tarefa substantiva e instrumental do diretor é criar as condições adequadas a realização dos objetivos para os quais a escola foi criada. Observando algumas realidades escolares do sistema público de ensino, verificamos que os diretores administram menos que para a atividade principal desempenhada pelos professores do que ela para os interesses da burocracia dominante externa a escola. Por esta razão estamos propondo a descentralização do processo decisório no interior das escolas públicas, buscando uma melhor adequação das relaçōes de poder que se estabelecem no interior da própria organização.

\section{Introdução}

A atuação competente dos administradores educacionais é uma tarefa crucial para o aprimoramento efetivo da escola. Especialmente no contexto do sistema público de ensino, onde o diretor de escola precisa mediar as relações entre as instâncias superiores da administração do ensino e seus "subordinados", seu desempenho eficaz torna-se muito difícil e complexo. Como administrador intermediário dentro do sistema de ensino (embora em sua ponta infërior) com a tarefa de implementar as diretrizes políticas geralmente decididas nos órgãos externos e superiores à unidade escolar, o diretor se vê na contingência de ter que éxpressar lealdade a seus superiores hierárquicos e manifestar apoio e

\footnotetext{
* Docentes da Faculdade de Educação da Unicamp.

** Doutoranda da Faculdade de Educação da Unicamp.
} 
solidariedade a seus subordinados imediatos. Neste conflito de papéis e de interesses, a tendência tem sido uma "opção preferencial" pelas instâncias superiores de poder, em prejuízo da identificação com os interesses da unidade escolar e de seus atores imediatos. Esta posição tem, geralmente, levado os diretores de escola a se verem como "traidores" de seus colegas professores e a criarem um clima hostil e negativo de trabalho, onde o respeito pela sua autoridade e liderança educacional tende a diminuir após o encerramento de cada nova greve na rede de ensino. Esta complexidade da atuação do administrador intermediário já foi também constatada por Keys (1982) no contexto da administração de empresas. Como observa Keys, o administrador intermediário para ser eficiente e competente em sua tarefa, precisa "olhar" para cima (a administração superior), para baixo (seus subordinados), para os lados (seus pares) e para fora (a comunidade). O administrador de escola, de modo semelhante, precisa desempenhar com eficiência todas estas mediações a fim de tornar seu trabalho dentro da escola um instrumento de facilitação e aprimoramento de sua atividade-fim. No entanto, esta atuação do diretor tenderá a se colocar tanto mais a serviço da burocracia superior do sistema quanto menores forem o grau de autonomia administrativa, pedagógica e financeira da unidade escolar e o grau de participação da comunidade local na vida da escola. Por outro lado, na medida em que crescer o grau de autonomia da escola, o papel mediador do diretor se deslocará da preocupação principal com as instâncias superiores e se voltará mais para o contexto interno da unidade escolar, onde terá que liderar e articular o trabalho dos seus professores e funcionários. Esta breve constatação empírica do papel mediador do administrador escolar, embora superficial, representa uma justificativa suficiente para uma análise teórica mais profunda da natureza mediadora do trabalho de administração escolar e sugere uma hipótese de pesquisa a ser melhor comprovada empiricamente. Neste trabalho, porém, trataremos apenas da perspectiva teórica da questão.

O próposito deste trabalho é discutir o conceito de administração educacional como processo dialético de mediação interna e externa à escola, mediação de relações de poder e mediação participativa dos diferentes agentes direta e indiretamente envolvidos no processo educacional. Neste processo, a participação dos agentes educacionais é condição essencial de melhoria da qualidade de vida humana coletiva, da qualidade da educação e da educação de qualidade. 


\section{Administração educacional como processo mediador}

Segundo as definições formais de mediação, esta constitui uma categoria secundária ou acessória da realidade. Nesta ótica, a mediação desempenha um papel simplesmente instrumental entre partes ou fenômenos substantivos de determinada realidade. No entanto, numa explicação mais dialética da realidade que pretenda captar o movimento, a passagem de um nível para outro, de uma coisa para outra ou de uma parte para outra (Mello, 1982),

"a dinâmica concreta das organizaçōes sociais e da sociedade como um todo mostra que a mediação é um processo essencial e substantivo, pois ela é parte intrínseca do conjunto de fenômenos componentes do todo social. Na realidade, a mediação como categoria concreta limita e determina significativamente as forças componentes do sistema social (Sander, 1984, p. 103).

Ainda segundo Benno Sander, "a mediação administrativa expressa todas as ações e interações mútuas e múltiplas, internas e externas, confluentes e antagônicas que ocorrem no sistema educacional." (p. 104)

Pode-se ter uma mediação interna e uma mediação externa. A mediaçầo interna refere-se aos processos ou às relaçōes recíprocas entre os diversos elementos intrínsecos à organização. A mediação externa indica as relações recíprocas entre as organizações e seu meio ambiente. Entre os agentes de mediação interna e externa do sistema educacional destacam-se a docência, a supervisão do ensino, a orientação educacional e a administração da educação. Neste conjunto de agentes complementares, é especialmente importante o papel mediador da administração educacional (Sander, 1984).

Do mesmo modo que a educação é uma das práticas sociais particulares da política como prática global da convivência humana, a administração da educação é, ao mesmo tempo, um ato político e um ato pedagógico. $\mathrm{Na}$ administração da educação existe uma superordenação do político sobre o pedagógico. Ou seja, o administrador da educação é, antes de tudo, um político e, como tal, precisa exercer suas funções com legitimidade, responsabilidade social e espírito público (Sander, 1984). No entanto, para exercer efetivamente sua função política, ele precisa estar tecnicamente preparado. É esta preparação técnica que lhe dará instrumentos eficientes e eficazes para exercer sua função com efetividade política e relevância cultural. Daí a necessidade, conclui Benno Sander (1984), da 
eleição do administrador educacional como estratégia política e de sua formação como preparação técnica. Neste contexto, os critérios de eficiência (capacidade de produção do máximo com o mínimo de tempo e.energia) e de eficácia (capacidade para alcançar determinados resultados) devem subordinar-se à efetividade (capacidade de produzir a solução desejada) e à relevância (qualidade da solução) como critérios políticos e culturais. Donde, poder-se concluir que a forma concreta da administração escolar poderá contribuir positiva ou negativamente para a qualidade da educação, acabando por incutir nos administradores e nos administrados um certo estilo de vida e de relacionamento entre as pessoas e uma certa visão do mundo e do ser humano.

\section{Administração educacional como mediação de relações de poder}

Outra dimensão que precisa ser explorada é a da administração como mediação de relações de poder. Corolário desta perspectiva é a questão da positividade do poder na sociedade e na escola. A necessidade de caracterizar a mecânica do poder que se expande pelas instituiçōes penetrando, por isso, no nível de toda estrutura social, encontra resposta na análise ascendente formulada por Foucault, em sua obra "Microfísica do Poder" (1984). Foucault estuda o poder não como uma "dominação centralizada" que se pluraliza, se difunde e repercute nos outros setores sociais de forma homogênea, mas como uma rede de dispositivos ou mecanismos a que nada ou ninguém escapa. Não existe exterior possível, limites ou fronteiras contra o exercício do poder. A luta que ele engendra não se pode travar de outro lugar senão dentro da própria rede do poder. Este está sempre presente e se exerce e funciona como uma multiplicidade de relações de força (Foucault, 1984).

A idéia básica que nos interessa é mostrar que o poder é luta, afrontamento, relação de força e não uma relação unilateral que impõe limites, oprime e castiga ao nível da lei ou da repressão. A essa concepção se opõe a positividade (não jurídica) do poder que dissocia de imediato os termos dominação e repressão e acrescenta um lado produtivo e transformador do poder. Transparece aí, portanto, uma riqueza estratégica, uma eficácia produtiva, uma positividade (Foucault, 1984). E particularmente esse aspecto que possibilita aos homens gerir suas vidas, utilizar, aproveitar e otimizar suas potencialidades ao máximo, aperfeiçoando continuamente suas capacidades. 
A implicação fundamental deste conceito de positividade do poder é de que o processo educacional e a própria prática da administração sejam tais, que possibilitem aos educandos e aos educadores desenvolverem e aprimorarem suas capacidades de ação e de participação no poder, a fim de contribuirem para a melhoria da qualidade de sua vida coletiva. A qualidade política da vida humana refere-se a este relacionamento do homem com o homem no interior do fenômeno do poder. A dimensão política, ao tratar da ocupação dos espaços do poder, "contém o horizonte da potencialidade humana" (Demo, 1987, p. 20), expressa a arte do possível e abre espaços para a perspectiva da criatividade humana. $O$ processo educacional e a participação de educadores, educandos e comunidade no poder de administrar e gerir a vida da escola, constituirá um instrumento fundamental de sua "potencialização" como pessoas e como "cidadãos institucionais". Neste sentido, acreditamos que, nas condições históricas atuais do país, a alternativa de poder viável, possível e mais adequada para as escolas é a co-gestāo, que se constitui numa superação dialética dos extremos do autoritarismo da escola tradicional, onde impera a figura do professor e a anulação da personalidade do aluno, e da autogestão extremada, que pretende negar todo poder e qualquer autoridade ao professor (Fontán Jubero, 1978). No sistema de cogestão escolar, haverá lugar para a autoridade do professor, para a participação do aluno e para o envolvimento dos pais e da comunidade no processo de decisão da escola. Neste contexto, o diretor terá o novo papel de agente transformador da escola numa autêntica instituição democrática, onde o espaço da participação estará assegurado a todos os seus membros.

\section{Mediação participativa e graus de participação no processo decisório}

A participação consiste na "parte de poder ou de influência exercida pelos subordinados em uma organização e considerada como legítima pelos mesmos e por seus superiores." (Sánchez de Horcajo, 1979, p. 17) Strauss (1963) entende a participação como uma forma de equilíbrio de poder que assegura aos subordinados, o envolvimento na escolha dos objetivos e/ou dos meios para conseguí-los.

A participação na gestão da escola implica no poder real de tomar parte ativa no processo educacional, tanto no nível microssocial como no macrossocial, por parte de todos os envolvidos nesse processo, ou seja, alunos, pais de alunos, professores, administradores do sistema educacional e da escola e mesmo grupos

Paidéia, FFCLRP-USP, Rib. Preto, 5, Agosto/1993. 
sociais organizados. Esta participação implica em que estes agentes possam ter um papel ativo nas decisões sobre a elaboração das políticas educacionais, na sua execução e no controle de sua aplicação (Sánchez de Horcajo, 1979).

A participação pode se dar em graus variados de intensidade, indo desde a simples informação que constitui o limite mínimo de participação, até a autogestão que representa o extremo máximo de participação e autonomia. Graus intermediários de participação são assegurados pela consulta facultativa ou obrigatória, pela elaboração e recomendação de opções concretas, pela colegialidade ou cogestão e pela delegação de poder. $O$ grau de participação e a relativa influência de administradores e administrados, no processo de tomada de decisōes, pode ser expresso num gráfico que apresenta o "continuum" da participação no processo decisório (Ver gráfico 1).

A participação por mera participação ou reação se dá quando os administrados são informados de uma decisão já tomada sem nenhuma consulta a eles. Neste caso, os administrados podem exercer certa influência reagindo à decisão se esta não lhes convém. Fica, porém, a critério da administração rever ou manter sua decisão inicial.

Gránco 1 - "Continuum" da participaçđo no processo decisório.

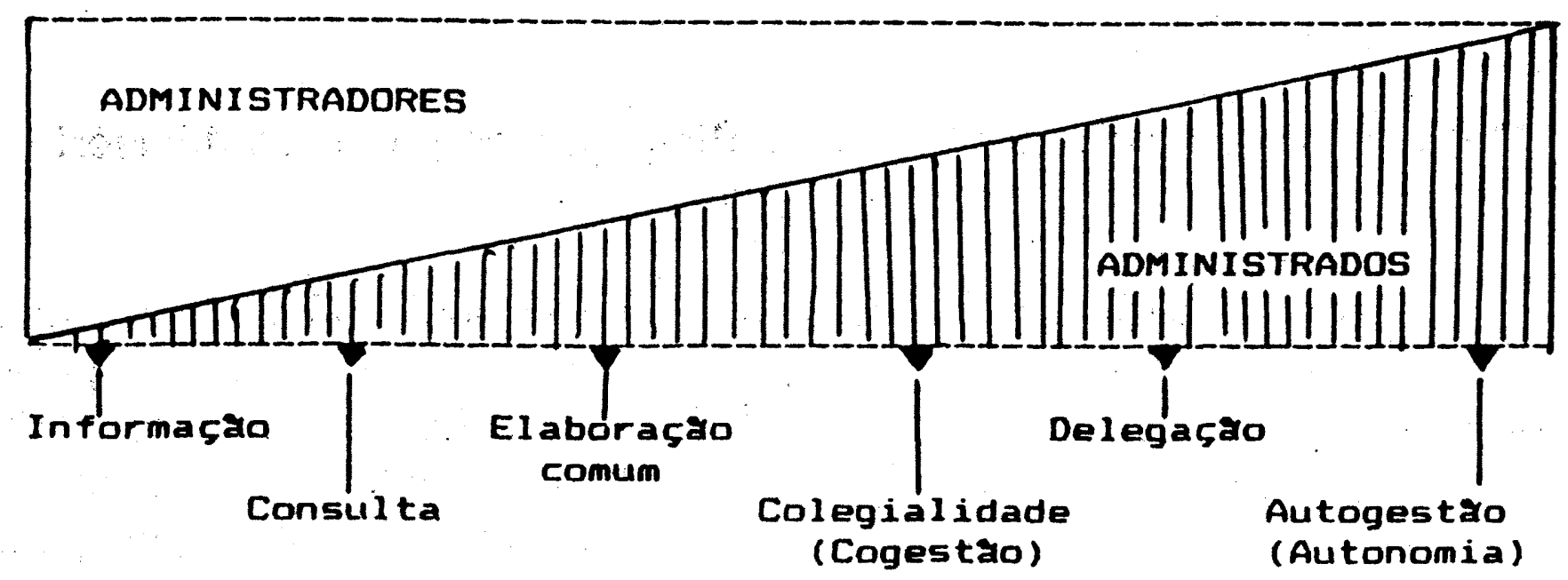

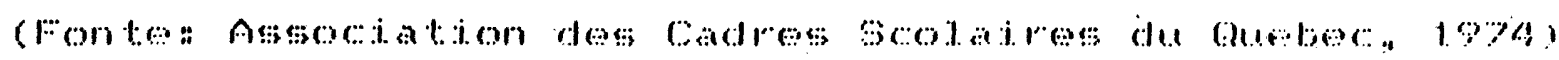


Dá-se a consulta facultativa quando a administração solicita sugestões aos administrados. Estes podem mostrar falhas, apresentar críticas ou fornecer dados úteis à solução buscada.

A consulta obrigatória ocorre quando os administrados têm direito de serem ouvidos. Suas sugestōes devem ser consideradas na tomada de decisão final, mas a decisão cabe sempre ao diretor.

A participação na forma de elaboração/recomendação se dá quando os administrados se envolvem na formulação, análise e avaliação de opções, e formulam recomendações precisas. Neste caso, a administração pode aprovar, modificar ou rejeitar as propostas encaminhadas, cabendo-lhe em última instância a decisão final.

A participação na forma de colegialidade ou cogestão permite que os administrados exerçam uma influência efetiva e direta na escolha ou rejeição de um plano de ação e na tomada de decisão. Neste caso, os colegiados (comitês, conselhos, congregações) são utilizados para a tomada de decisão comum.

Através da delegação de poder, os administrados adquirem um poder de decisão, em determinados segmentos da administração, antes reservados a instâncias superiores. A administraçào define os limites de autonomia e de poder delegado. Pela delegação, a pessoa delegada possui autoridade para tomar suas decisões sem prévia consulta a seus superiores. Se tiver que consultá-los antes de tomar suas decisões, não possui delegação plena de poderes.

A autogestão ou autonomia plena implica que a pessoa ou entidade determina por si mesma suas diretrizes e escolhe os meios e controles pertinentes sem referência a uma autoridade externa. No campo da educação e no atual contexto histórico das sociedades humanas só é possível pensarmos numa autonomia relativa para determinadas questões e para certas instâncias do sistema educacional.

A participação na gestão da escola pode dar-se numa gama variada de possibilidades tanto na integração de alguns ou de todos os grupos envolvidos na escola, como no grau de participação de cada um destes grupos (Sanchez de Horcajo, 1979). Pode-se atribuir aos pais e professores o poder de co-decisão e conceder aos alunos apenas o poder de consulta. Podem variar os tipos de grupos representados no colegiado da escola e seus respectivos graus de participação. $O$ avanço nesta representação e participação vai depender do grau de consciência política dos diferentes segmentos e interesses envolvidos na vida da escola. Participação não se concede; participação se conquista. 
O grau de participação também pode variar para as diferentes decisões (Sanchez de Horcajo, 1979). A nível microssocial, ou seja, a nível da escola, pode haver a co-gestão nas questões em que ela tem autonomia. A nível macrossocial, dificilmente cada escola poderia sequer ser consultada diretamente para a definição das diretrizes gerais.

A participação na escola pode ainda ser formal ou institucionalizada, e informal, ou seja, de forma independente dos instrumentos oficiais de participação. Em muitos casos, a participação informal é mais importante e mais eficaz que a formal.

A participação pode também dar-se de forma direta e indireta através de representação autêntica (Sánchez de Horcajo, 1979). Nos níveis mais elementares, como a sala de aula, é viável e recomendável a participação direta. No nível da gestão da escola e mais ainda no nível do sistema educacional, a participação só é efetiva através da representação ou delegação.

Como afirma Sánchez de Horcajo (1979),

"Para um "tipo ideal" de modelo de gestão participativa, a participação deve considerar-se paritária para todos os grupos e pessoas que intervêm no ensino, abarcando todas as formas possíveis (direta, indireta, formal e informal), chegando a ser possível, no "continuum" do processo decisório, até o grau de co-decisão ou colegialidade na elaboração e desenvolvimento do projeto educacional tanto a nivel macrossocial como microssocial". (p. 22)

\section{Administração participativa como administração de qualidade}

Na sua dimensão substantiva e positiva, a qualidade pode ser identificada com a participação que é o cerne da criação política. "É a conquista humana básica na dimensão da qualidade." (Demo, 1987, p. 21) Pedro Demo (1980, 1985, 1987) considera que existe, ao lado da pobreza sócio-econômica, uma pobreza política que consiste fundamentalmente na falta de participação. $O$ pobre politicamente é a pessoa ou grupo que é massa de manobra, objeto de dominação e manipulação, instrumento a serviço dos outros. Na esfera do poder, o pobre aparece apenas como "matéria de dominação, na senzala da vida, coibido em sua autodeterminação... Do sujeito já não sobra quase nada, pois é objeto, instrumento, escravo. (Demo, 1987, p. 21) Esta violência moral mutila e mata de outra maneira, acabando com a qualidade de vida. 
Pedro Demo (1987) considera que dar importância à pobreza política significa tratar das precariedades dos processos participativos.

"Pobreza política é falta de participação, é a coerção da conquista da participação, é a inconsciência histórica e imposta da necessidade de autodeterminação. Nossa sociedade é miserável neste sentido, porque ainda é uma senzala. Não somos um povo capaz de auto-determinação e de conquistar seu espaço próprio e criativo, mas massa de manobra nas mãos de uma oligarquia tão restrita quanto tacanha." (Demo, 1987, p. 22)

Qualidade de vida humana refere-se fundamentalmente à dimensão do ser e não do ter. Na qualidade vale o melhor e não o maior, o intenso e não o extenso, o envolvente e não o violento, a impregnação e não a pressão. A qualidade é de estilo cultural, artístico, lúdico e sábio (Demo, 1987).

Dimensão relevante da qualidade é a identidade cultural comunitária. É a identidade cultural que distingue uma comunidade de um bando de gente. A coesão do grupo constrói a envolvência solidária e "é, de certo modo, a parteira da participação, porque dá à luz a força aglutinadora de um grupo humano que decide se autodeterminar, superando sua condição de massa de manobra.(Demo, 1987; Arantes, 1982; Feijó, 1983; Canclini, 1983) Liberdade, autonomia, autodeterminação estão no cerne do sentido e da qualidade da vida humana, que é participar. Ou, por outras palavras, o caminho político para a realização de uma forma qualitativa de vida humana coletiva na sociedade e na educação é o da participação (Sander, 1984). Como acrescenta Benno Sander (1984), a participação favorece a definição justa dos espaços de contribuição e de beneficiamento individual da experiência coletiva. A participação afasta o perigo das soluções dogmáticas e fechadas, desprovidas de sínteses superadoras. A participação, enfim, é direito e dever de todo cidadão que integra qualquer comunidade ou sociedade democrática. (p. 146)

Participação e democracia na sociedade e na escola, eis os instrumentos de construção de uma sociedade com qualidade de vida humana para todos. A escola é uma instância, junto com outras organizaçōes da sociedade, em que é possível construir a democracia. No entanto, para que essa possibilidade se concretize, é preciso que a própria escola e as demais organizaçōes da sociedade adotem práticas democráticas. A adoção de um estilo participativo de 
administração da educação constitui uma forma concreta de contribuir para o desenvolvimento da democracia na escola e na sociedade. A democracia, porém, não é um fim em si mesmo, mas a mediação política para o alcance de uma qualidade substantiva de vida humana coletiva como objetivo ético da escola e da sociedade (Sander, 1984).

Existem diversas formas específicas de participação na administraçào da educação ou no governo da sociedade. No entanto, o tema comum e central, subjacente a todas as formas de participaçào e de administração, é o do processo decisório. Participar na administração educacional é, essencialmente, tomar parte efetiva no processo das decisões que afetam a vida da escola e as aspirações e interesses de seus integrantes.

Como poderoso antídoto ao autoritarismo institucionalizado na burocracia formal da escola e à ação dogmática de grupos minoritários de qualquer orientação ideológica, propomos a participação coletiva como paradigma da administração da escola e a mediação democrática como seu estilo mais adequado de exercício do poder, tendo em vista o objetivo ético da qualidade de vida humana para todos na sociedade.

A tradição brasileira é de autocracia, seja no governo da sociedade, seja na administração da escola. A saída para o país e para a escola é a passagem da autocracia para a democracia.

"Descentralizar o poder é abrir canais para que a população possa estar informada e participar da solução dos problemas que lhe dizem respeito. Esta tarefa é a de construção da democracia e do fortalecimento da sociedade civil. E para essa luta todos estamos convocados". (Montoro, Folha de São Paulo, 7 de janeiro de 1991).

Também a escola está convocada para a luta de se transformar numa instituiçāo democrática com poder de decisão sobre aspectos substantivos de sua estrutura e funcionamento, a fim de que seus membros passem da posição de "súditos" para a de "cidadãos institucionais", onde, aliás, passam uma grande parte de suas vidas. 


\section{Educação de Qualidade}

Durante a década de 80 , a preocupação de um grande nụ́mero de países, especialmente dos países do primeiro mundo, foi de melhorar a qualidade da educação, uma vez que o problema da quantidade estava praticamente resolvido. Este interesse pela qualidade tem-se manifestado claramente em suas políticas e planos para melhoria da educação em todos os seus níveis e aspectos. Sāo famosos, nos Estados Unidos, os inúmeros relatórios publicados na década de 80, propondo medidas para a melhoria da qualidade da educação americana (Gross e Gross, 1985).

No contexto brasileiro, a preocupação com a qualidade da educação surgiu concomitantemente com o processo de redemocratização do país, quando ficou evidente que o processo de expansão quantitativa das redes públicas de ensino se mostrava insuficiente para levar a uma autêntica democratização do ensino público do país. A partir desta época, educadores e pesquisadores passaram a se voltar com certa insistência para o problema, tentando assinalar as deficiências mais gritantes de nosso sistema educacional e suas desastrosas consequências, bem como investigar os fatores que as explicam e buscar alternativas de solução.

A palavra "qualidade" constitui um critério que se utiliza para avaliar determinadas características dos objetivos, das condiçōes, dos processos e do desempenho de um sistema educacional. A qualidade pode ser buscada na definição das metas, na estrutura, no currículo, na prática pedagógica e no próprio sistema de avaliação adotado pelo sistema educacional. Em todos estes componentes do sistema, há lugar para a busca de excelência e qualidade superior.

A expressão "qualidade da educação" no quadro dos sistemas educacionais admite uma variedade de interpretações segundo a concepção que se adota sobre o caráter da condição humana, sobre seu papel no espaço de uma realidade sócio-política determinada e sobre o que se considera pertinente que as instituições educacionais proporcionem. Se se considera, por exemplo, que uma educação de qualidade seja aquela que proporciona o desenvolvimento das capacidades que permitam aos indivíduos participarem de modo crítico, responsável e criativo na construção de uma ordem social mais justa onde todos tenham a oportunidade de conseguir plena realização pessoal e profissional, torna-se necessário criar uma série de condições objetivas, tanto em nível da escola como da sociedade, para de fato garantir tal educação de qualidade para todos.

Paidéia, FFCLRP-USP, Rib. Preto, 5, Agosto/1993. 
Entre estas condições de qualidade positiva ou negativa da escola está o seu tipo de administração (Lafourcade, 1988).

\section{Conclusão}

Estas reflexões teóricas podem ter importantes implicaçōes práticas para o cotidiano do administrador escolar. A título de conclusão deste trabalho, algumas delas serão arroladas a seguir.

Em qualquer organização, a tarefa substantiva e instrumental da administração é criar as condiçōes adequadas à plena realização dos objetivos para os quais aquela foi criada - a dimensão substantiva de suas atividades-fim. Neste seu papel de meio para a realização das metas da organização, a administração, às vezes, pode subverter sua tarefa e tornar-se fim em si mesma. Neste caso, dá-se o processo de burocratização que representa a perversão da racionalidade da burocracia. Pensada para ajudar a organização a realizar sua missão, a administração nesta hipótese impede seu desempenho eficaz. Aplicando esta análise ao contexto da escola pública, tem-se o absurdo de sistemas de ensino de alguns Estados do país que consomem cerca de $50 \%$ de seus recursos financeiros na burocracia e não na melhoria da qualidade do ensino. Pode-se também manter um sistema de ensino para dar emprego a milhares de administradores e professores e não para ensinar de verdade. Chega-se até ao absurdo de se ter sistemas de ensino que concedem vantagens e atendem aos interesses dos professores em prejuízo dos alunos. Ou seja, tem-se escolas para dar empregos a professores e administradores e ocasionalmente para ensinar. Num sistema destes, geralmente com uma administração fortemente centralizada, o administrador da unidade escolar faz apenas o ridículo papel de "menino de recado" das instâncias superiores e, se se preocupa com o trabalho pedagógico da escola, viverá em permanente frustração por ter que administrar as frequentes "licenças de saúde" de seus professores e por não ter poderes para criar um corpo estável e competente de docentes para sua escola.

$\mathrm{Na}$ administração centralizada do sistema de ensino, o administrador da unidade escolar tende a privilegiar seu "olhar" para as instâncias superiores da administração e, nas épocas de conflito trabalhista, na ânsia de manter as boas relações com o poder das esferas superiores, inclina-se a se comportar como "capataz" do patrão e a abandonar a solidariedade com os profissionais de sua escola. Sua mediação se dá apenas no interesse da burocracia superior. $O$ resultado 
será, no desfecho da crise (em geral, greves), um clima de hostilidade e desconfiança entre ele e seus professores, o que implicará num ambiente inadequado para o trabalho pedagógico sob sua liderança e coordenação.

Numa estrutura descentralizada e de considerável autonomia da unidade escolar, o administrador da escola terá espaço para o desempenho de um adequado e eficaz equilíbrio e mediação entre os objetivos da escola (a dimensão nomotética da tarefa) e os objetivos das pessoas (a dimensão ideográfica dos interesses dos indivíduos na organização) (Santos Filho, 1992). Neste trabalho, será tão mais eficaz quanto mais engajar a todos os membros da comunidade escolar no processo de sua gestão através da participação autêntica. A participação nas decisões tende a gerar o compromisso e o engajamento na busca e no alcance da missão da escola. Neste novo contexto, o papel do diretor será o de coordenar e estimular o auto-governo da unidade escolar. Neste novo tipo de administração, o diretor deixará de ser um capataz dentro da escola e passará a representar e defender os autênticos interesses da educação dos alunos (Santos Filho, 1983). Nesta nova escola, e a partir dela, serão criadas as condições para a busca da excelência do trabalho pedagógico, sua única razão de ser.

\section{Referências Bibliográficas}

Arantes, A. A. O que é cultura popular. Sáo Paulo: Brasiliense, 1982.

Association des Cadres Scolaires de Quebec. Colóquio Internacional de Quebec sobre L'Administration de l'éducation en pays francophones. Quebec, 27-27 de setembro de 1974

Canclini, N. G. As culturas populares no capitalismo. São Paulo: Brasiliense, 1983.

Demo, P. Pobreza sócio-econômica e política. Florianópolis: Editora da Universidade Federal de Santa Catarina, 1980.

Demo, P. Ciências sociais e qualidade. São Paulo: Almed, 1985.

Demo, P. Avaliação qualitativa. São Paulo: Cortez Editora e Editora Autores Associados, 1987.

Feijo, M. C. O que é política cultural. São Paulo: Brasiliense, 1983.

Fontán Jubero, P. La escuela y sus alternativas de poder. Barcelona: Ediciones CEAC, 1978.

Paidéia, FFCLRP-USP, Rib. Preto, 5, Agosto/1993. 
Foucault, M. Microfísica do poder. Rio de Janeiro: Graal, 1984.

(Gross, B. and Gross, R. (Eds.) The great school debate: Which way for American Education? New York: Simon \& Schuster, Inc., 1983.

Keys, B. Four Faces of the Efficient Intermediate Manager. California Management Review 24(4), Summer 1982.

Lafourcade, P. Calidad de la Educación. Buenos Aires: Ministério Educación y Justicia, Dirección Nacional de Información, Difusión, Estadística y Tecnologia Educativa, 1988.

Mello, G. N. de Magistério de 1o. grau: Da competência técnica ao compromisso político. São Paulo: Cortez Editora e Autores Associados, 1982.

Montoro, F. Sua majestade o presidente do Brasil. Folha de São Paulo, A-3, 7 de janeiro de 1991.

Sánchez de Horcajo, J.J. La gestión participativa en la enseñanza.(Presupuestos sociopedagógicos) Madrid: Narcea, S.A. Ediciones, 1979.

Sander, B. Consenso e conflito: Perspectivas analíticas na pedagogia e na administração da educação. São Paulo: Pioneira; Rio de Janeiro: Universidade Federal Fluminense, 1984.

Santos Filho, J. C. dos Administração educacional e desenvolvimento social. Revista Brasileira de Administração da Educação 1(1), jan./jun., 1983.

Santos Filho, J. C. dos O recente processo de descentralização e de gestão democrática da educação no Brasil. Faculdade de Educação da UNICAMP, 1992. (Mimeo).

Strauss, G. Some notes on power equalizations. In: The Sociology of Organizations. New York, 1963.

\section{ABSTRACT}

This paper was inspired by the following statement: the management of specialized organizations as schools, is critical for its effective development. The schoolmaster's essential and instrumental task is to provide suitable conditions to accomplish school aims. By observing some public schools realities we can see that schoolmasters do their management less for the main teaching activities than for the ruler burocracy external to schools. That's why we proposed decentralization of the decision making process inside public schools, aiming better adequacy to power relationships established inside the institution itself. 